\title{
Article
}

\section{Raising our game: The necessity and progression of expertise-based training in applied sport psychology}

Cruickshank, A, Martindale, A., and Collins, D.

Available at http://clok.uclan.ac.uk/23510/

Cruickshank, A ORCID: 0000-0002-8893-2341, Martindale, A., and Collins, D. ORCID: 0000-0002-7601-0454 (2020) Raising our game: The necessity and progression of expertise-based training in applied sport psychology. Journal of Applied Sport Psychology, 32 (3). pp. 237-255. ISSN 1041-3200

It is advisable to refer to the publisher's version if you intend to cite from the work. http://dx.doi.org/10.1080/10413200.2018.1492471

For more information about UCLan's research in this area go to http://www.uclan.ac.uk/researchgroups/ and search for <name of research Group>.

For information about Research generally at UCLan please go to http://www.uclan.ac.uk/research/

All outputs in CLoK are protected by Intellectual Property Rights law, including Copyright law. Copyright, IPR and Moral Rights for the works on this site are retained by the individual authors and/or other copyright owners. Terms and conditions for use of this material are defined in the policies page.

\section{CLoK}

Central Lancashire online Knowledge www.clok.uclan.ac.uk

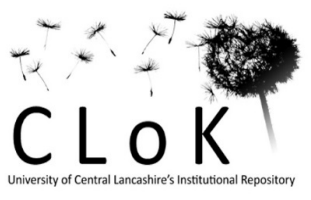


Raising Our Game: The Necessity and Progression of Expertise-Based Training in Applied Sport Psychology

\author{
Andrew Cruickshank ${ }^{1,2}$, Amanda Martindale ${ }^{3}$ and Dave Collins ${ }^{1,2}$ \\ 1: Institute of Coaching and Performance, University of Central Lancashire \\ 2: Grey Matters for Performance Ltd \\ 3. Institute of Sport, P.E., \& Health Sciences, University of Edinburgh
}

Accepted author version for: Cruickshank, A., Martindale, A., \& Collins, D. (2018). Raising

Our Game: The Necessity and Progression of Expertise-Based Training in Applied Sport

Psychology. doi: 10.1080/10413200.2018.1492471

Published online: July 10 $10^{\text {th }}, 2018$ 


\begin{abstract}
At present, training in applied sport psychology chiefly targets and accelerates professional competence. However, theory and evidence suggests that our clients would experience significant benefit if our training targeted and accelerated professional expertise rather than just competence. Specifically, we argue that expertise-based training can: (a) help trainees to go on to break the "thinking ceiling" of competence; (b) foster a more independent, flexible, and creative form of practice; and (c) support a longer-term and more practitioner-centred training philosophy. To deliver these benefits, we then conclude by outlining some key principles for the progression of expertise-based training in applied sport psychology.
\end{abstract} Keywords: accreditation, adaptability, cognition, competency, professional training 


\section{Raising Our Game: The Necessity and Progression of Expertise-Based Training in}

\section{Applied Sport Psychology}

As one part of the push to further professionalise applied sport psychology (hereafter ASP), there has been a notable and welcome surge of literature on training systems and processes (e.g., Eubank 2016; Fitzpatrick, Monda, \& Wooding, 2016; Hutter, OldenhofVeldman, Pijpers, \& Oudejans, 2017; Martin, Winter, \& Holder, 2017). As well as providing the chance to reflect on recent approaches and the views of our colleagues, a number of these contributions have also, however, reminded us of the many inconsistencies that still surround professional training. One particular area of difference relates to the primary goals and methods of formal development (cf. Collins, Burke, Martindale, \& Cruickshank, 2014; Fletcher \& Maher, 2013, 2014). For example, the following view summarises some common bones of contention:

Recently, in the context of professional training and development in sport psychology, I've read or heard worrying statements such as 'why be competent when you can be expert?' and 'professional decision-making is king'. [My trainee's] case study [published in the same journal issue] reminds us just how ridiculous (and potentially dangerous) such views can be. No one can progress from being a novice trainee to expert practitioner after a just few years of supervision, especially in all aspects of practice, and although decision making skills are clearly important, many other applied and interpersonal competencies are also vital to develop. It concerns me that some nonchalantly dismiss the ethical obligation of competence and focus on such narrow aspects of professional practice. (Fletcher, 2017, p. 72)

With regard to this particular view, we agree with many parts. Indeed, it is clear that no one can progress from novice to expert practitioner in a few years. We also agree that many areas of ability are required beyond decision making. However, while we "furiously agree" with 
these points, other parts of this quote remind us that further debate and clarity is needed on what the goal of training should be and how this may be best achieved; especially if our literature is to optimally inform our training systems moving forwards.

More specifically, although expert status is clearly an inappropriate goal for the training-to-accreditation phase, our first aim in this paper is to argue that the development of expertise is. Moreover, evidence suggests that there are significant advantages - relating to process and outcome - from targeting and accelerating expertise rather than just competence during (and post) formal training; despite the latter having been preferred by most training bodies (e.g., Association for Applied Sport Psychology, British Psychological Society, European Federation of Sport Psychology, Psychology Board of Australia). Following this, our second aim is to consider how we could move forward with expertise-based training and, in tandem, highlight the central role that professional judgment and decision making (hereafter PJDM) needs to play. Finally, recognizing that expertise-based training is already established as best practice in many other fields (e.g., the military, avionics, and medicine: Ericsson, 2009), we therefore argue that an expertise and PJDM focus is essential if training in ASP is to enable a more proficient service. However, to set the context for our case, it is important to first provide an overview of current approaches to training in ASP, draw attention to some key terms in these approaches, and frame these approaches against the basic nature of ASP.

\section{Framing Our Case}

\section{Current Approaches to Training in ASP}

Fundamentally, all training systems of which we are aware have been developed with the purpose of better regulating and enhancing ASP. Indeed, before the most recent evolution of these systems, it was widely perceived that limitations in training were hampering our collective status and impact; as well as our ability to protect the public. As a result, many 
professional bodies responded by developing a more formal certification process which, in cases such as the US, UK, and Australia, have centred on the development of the trainee's competence. As similarly defined by these bodies, the level of competence needed for certification reflects "underpinning knowledge and . . core competencies" (British Psychological Society, 2018, p. 4, emphasis added), an "acceptable level of knowledge and skill" (Association for Applied Sport Psychology, 2017, p. 12), or "core competencies . . a a level consistent with the depth and expertise expected of an entry-level endorsed practitioner" (Psychology Board of Australia, 2018, p. 6, emphasis added).

To achieve this core and acceptable level of performance, trainees are required to gain higher education degrees either alongside or before a period of supervised practice with an experienced and suitably qualified practitioner. As suggested by the preceding paragraph, these activities are all framed by a competency model, which has been designed with the aim of developing and validating trainees in a more standardised and objective fashion. More specifically, these competencies are housed in a range of domains and invariably reflect an "understanding" or "knowledge of" specific topics or the ability to deliver or demonstrate certain procedures and behaviours (e.g., "competence in communicating . . . ethical obligations to others": Psychology Board of Australia, 2017, p. 23). As such, there is little explicit mention or detail of cognitive skills such as decision making, with competency models reflecting an argument that "behavioral anchors . . . ultimately determine an individual's competence" (Fletcher \& Maher, 2014, p. 173). On completion of the relevant education and supervised experience, trainees are then required to pass a final assessment, which typically involves a formal exam (e.g., Association for Applied Sport Psychology, 2017; Psychology Board of Australia, 2018) or interview (British Psychological Society, 2018). Up to and including this final stage, the trainee's competence is ultimately evaluated and validated by independent assessors; who are often anonymous and primarily (or 
sometimes exclusively) base their judgments on written reports, forms, activity logs, and exam scores, with little if any direct contact with the trainee.

In summary, training in ASP is currently driven by the pursuit of an acceptable level of competency across all trainees. More specifically, training bodies require trainees to fulfil their competency models by acquiring and demonstrating blocks of knowledge, procedures, and behaviours to a prescribed (and sometimes minimum acceptable) standard. As such, competence in ASP is conceptualised by our training system as, first and foremost, a function of: (a) how well an individual understands various principles and constructs; and (b) how well they can deliver core procedures and behaviours. Or, in other words, what they know and what they can do, framed against prescribed expectations.

\section{Drawing Attention to Some Key Terms}

Before we compare current approaches to training in ASP against an expertise-based alternative, it is important to emphasize the difference in terms that feature throughout this paper. In particular, the use of competency, competence, and expertise are the crucial issues here and the reader is referred to Collins et al. (2014) for a detailed discrimination of all three. For the present purpose, however, we underline that the competence that is currently referred to by training bodies represents an acceptable standard of practice: characteristics of which are often evaluated through observable behaviours framed as competencies. More broadly, competence, like the construct of expertise, refers to a practitioner's integrated skills (i.e., "they have the competence or expertise to do x, y, z"). However, and as we shall go on to argue, aiming to develop an expertise-equipped practitioner is different from aiming to develop a competence- (and competency-) equipped practitioner in both process and outcome.

To clarify further for now, our work in other fields shows that professional practice often involves a mix of factors, which are consequently best addressed by a mix of methods. For example, correct versus incorrect techniques are best addressed as competencies: such as 
“can this climbing coach tie this knot?" (cf. Collins \& Collins, 2016). For the majority of interpersonal interactions, however, as typical in coaching and arguably almost universal in ASP, a more nuanced, "shades of grey" approach to evaluation is needed (e.g., "what options did you consider and why did you select the one you did over others?"): hence our emphasis on expertise-focused approaches in the remainder of this paper (Collins et al., 2014). Indeed, expertise centers on the ability to make value judgements to identify and deploy the optimum blend of techniques to meet complex and dynamic situations. In this way, our rationale for an expertise-based approach in ASP training lies in the basic nature of ASP itself. We will now describe this basic nature before highlighting the advantages of practitioners being expertiseequipped rather than just competence-equipped.

\section{The Basic Nature of ASP}

Before any evaluation of the pros and cons of different approaches to training in ASP, it is important to critically reflect on the outcomes that the "users" (i.e., our training bodies and trainees) are attempting to deliver against the basic nature of ASP. In this respect, Kaslow et al. (2007) have earlier emphasised that the preparation of psychologists should operate relative to the performance required of them professionally; which, in our case, we take as the level needed to operate as a fully certified practitioner in a sport, exercise, or performance field. As described in the prior subsection, many training bodies in ASP have consequently conceptualized the outcomes of training as core competencies. However, if we want to support others to become more proficient at the process of sport psychology practice, we need to focus less during the final stages of training on what a practitioner understands and can do (i.e., their knowledge inputs and behavioral outputs) and more on why and how they do what they do (i.e., the cognitive production line) (cf. Martindale \& Collins, 2010; Poczwardowski, 2017). 
With this focus, it is also important to recognize that practitioners in ASP can - and usually do - work with a range of clients, goals, and relationships in a range of environments (e.g., from participation to performance sport, individual to team sport, youth to senior sport). Effective practice (i.e., that which delivers client-benefiting outcomes) therefore relies on the ability to apply broad theories, principles, and interventions to specific clients, contexts, and challenges; even if we practice in just one type of setting (Portenga et al., 2016). Certainly, beyond some broad ethical, legal, and professional requirements, there is rarely a "right" or "wrong" way to operate in ASP. For example, there are effectively endless ways to develop rapport, design support programs, and deliver interventions with our clients. Problematically, our work also takes place in a low validity environment, where predictable or attributable outcomes are in short supply; for example, the improvement in a young athlete's confidence might be due to direct intervention by the practitioner but it could also, among other possibilities, be due to their own reflection or a change in dynamics with their coach and parents. Thus, ASP is in stark contrast to the higher validity environments of other professions such as weather forecasting (Shanteau, 1992; Shanteau \& Weiss, 2014; Tracey, Wampold, Lichtenberg, \& Goodyear, 2014) and the chance to repeat and hone "routine skills" is limited, if indeed many such routines exist. In this respect, we know that similar approaches or sessions can have different effects on different clients, or even effects on some but not on others.

Therefore, given that we rarely apply routine skills in routine situations and have to look for the best answer rather than the right answer in the given context, ASP obviously requires much complex thinking. Effective practice demands cognitive skills all the way from slowed down and deliberate thinking (e.g., for designing a support program) to rapid and cue-based thinking (e.g., responding to a client's emotional response in-session); all framed by an evolving philosophy and case-specific theoretical orientation (cf. Martindale \& 
Collins, 2005, 2012, 2013). Notably, these features are also characteristic of ASP during training; or at least they should be if we are to train as we perform in the workplace. For example, even delivery of simpler support - such as goal setting with an individual performer - requires trainees to fit their knowledge of general principles to the specific context (e.g., the athlete's profile, the demands of their sport, the nature of their environment) then adapt within the session to the evolving responses of the client. As such, the primary implication is that we need to foster skills that help trainees to work independently, flexibly, and creatively in both the short and long term; in other words, a focus which leads us to target the practitioner's thinking skills.

This cognitive focus becomes particularly apparent when we recognize that it is our thinking that drives how we behave (or intend to behave), provides the rationale that we must have behind our actions (in "worst case" scenarios especially), allows us to self-regulate, and helps us to keep learning after completing our formal training (Martindale \& Collins, 2005, 2007, 2012; Poczwardowski, 2017). This is not to say that overt behaviours are not crucial of course. For example, the impact of a practitioner's thinking (such as deciding where, when, and how to facilitate a difficult conversation with an athlete and coach) will only be optimal if they have the interpersonal skills to deliver on their intentions (i.e., the ability to draw out the common ground with empathy for both). However, if we accept the basic nature of ASP as defined above, then how we think is the primary element of a practitioner's long-term "engine" and we therefore require training that is weighted more toward cognitive than behavioural skill development. To reiterate, the development of one's behavioral repertoire is essential if we are to act as well as think adaptively; however, it is our ability to perceive, evaluate, judge, and plan (i.e., our PJDM) that enable us to select the most appropriate behaviors and mesh these in the best way at the best time. 
These arguments become ever more valid as the practitioner (hopefully) continues to grow after completing their apprenticeship of accreditation. Thus, not only is the thinking process essential during training (cf. ideas on cognitive apprenticeship in Martindale and Collins, 2010) but it seems even more important to drive the continued development postaccreditation. In short, if we stop thinking we stop growing. Now turning to the first aim of our paper, we argue that this thinking can be better supported by equipping trainees with expertise rather than just competence (and competencies) during formal training.

\section{Building our Professional Engine: The Advantages of Being "Expertise-Equipped" over "Competence-Equipped"}

As a starting point for comparing competence and expertise, it is sensible to consider definitions of both. As reported before in ASP literature (e.g., Collins et al., 2014; Fletcher \& Maher, 2014), Epstein and Hundert (2002, p. 227) have defined competence as:

The habitual and judicious use of communication, knowledge, technical skills, clinical reasoning, emotions, values, and reflection in daily practice for the benefit of the individual and community being served .... [It is also] defined by the ability to solve ambiguous problems, tolerate uncertainty, and make decisions with limited information".

In short, higher levels of competence enable practitioners to better apply themselves and their skills to different challenges in different contexts; a perspective which is consistent with the construct of expertise or, more specifically, the increasingly popular concept of adaptive expertise (Ward et al., 2017). Notably, however, this desirable attribute will be rather difficult to evaluate against a competency range statement. At the very least, the decision making inherent in Epstein and Hundert's definition of competence will also surely require some consideration of the practitioner's rationale that is currently under-emphasized by many 
training programs (e.g. Association for Applied Sport Psychology, 2017; British Psychological Society, 2018; Psychology Board of Australia, 2018).

Indeed, adaptive expertise is deemed to reflect an "an individual's ability to perform [i.e., to think and act] flexibly and innovatively in novel and unstructured situations" (Tozer, Fazey, \& Fazey, 2007, p. 55); or, similarly, "timely changes in understanding, plans, goals, and methods in response to either an altered situation or updated assessment about the ability to meet new demands, that permit successful efforts to achieve intent" (Ward et al., 2016, p. 20, as cited in Ward et al., 2017). In short, adaptive expertise is shown by those who can consciously and effectively vary their performance appropriately across contexts. Adaptive expertise is therefore distinct from the routine expertise that is "gained through routine practice" (Tozer, Fazey, \& Fazey, 2007, p. 61) and helps individuals to "perform procedural skills efficiently" (Hatano \& Inagaki, 1986, p. 28). More specifically, those with adaptive expertise:

Have a depth of understanding that allows them to use their intellectual, physical, emotional, and social capabilities to identify and interpret changes in systems .... Adaptive experts are able to flexibly and more smoothly translate an experience into better understanding, even when those experiences have not been anticipated. They accept uncertainty, and have greater capacity to act appropriately when faced with unanticipated ... outcomes. (Fazey, Fazey, \& Fazey, 2005, para. 19)

So, based on their broad definitions, competence and adaptive expertise therefore appear to have much in common. As such, training systems that are oriented toward competence or adaptive expertise should foster similar general abilities in practitioners; for clarity, abilities that help trainees to practice relative to the client, context, and challenge (e.g., tailoring a goal setting intervention to a senior athlete striving for Olympic success in an individual sport versus a young athlete striving for success over the next month in a team sport). 
However, although competence and expertise appear similar and are certainly not diametrically opposed (as also recognized in Fletcher \& Maher, 2014), they are also not equivalent. Reflecting their development in distinct bodies of literature, competence and (adaptive) expertise instead provide different perspectives on independent, flexible, and creative practice. Indeed, these constructs vary with respect to: (a) the level of learning and performance that they can support in the long-term; (b) their breadth and depth of evidence on the development of thinking skills; and (c) their underpinning philosophy of professional development. More specifically, and as the following subsections on the advantages of expertise will outline, literature suggests that expertise-based training can: (a) build the potential for trainees to break the "thinking ceiling" of competence; (b) exploit a stronger empirical base than competence for developing independent, flexible, and creative practice; and (c) work from a longer-term and more practitioner-centred philosophy than competence. We will now describe these advantages and the evidence supporting them in this order.

\section{Advantage I: Building Potential to Break the "Thinking Ceiling" of Competence}

As stressed earlier, ASPs need to be agile thinkers if they are to deliver a consistently optimal service to their clients (relative to their current levels of proficiency) in the dynamic, complex, and uncertain contexts that they operate. Problematically for competence, however, leading figures have reported that competence is not enough for optimal agility. Specifically, Kaslow et al. (2007, p. 447) have argued that "capability [needs to be assessed] in addition to competence":

[Capability] incorporates and extends the notion of competence. Capability refers to the extent to which competent individuals can adapt their skills to new contexts and situations, generate (rather than simply acquire) new knowledge, and continue to improve their performance . . . Capability is the enhancement of competencegenerally achieved through formative or summative feedback on one's performance, 
self-assessment, and coping with unfamiliar contexts and challenges to one's competencies. It is the confluence of competence and lifelong learning, an ongoing professional developmental conceptualization [emphasis added].

As emphasized by a number of others (e.g., Fraser \& Greenhalgh, 2001; Kennedy, Cameron, \& Monsen, 2009; Stephenson \& Yorke, 1998), capability thereby zones in on an individual's ability to "deal effectively with the turbulent environment in which they live (or work) by possessing an all-round capacity to manage continual change" (Gardner, Hase, Gardner, Carryer, \& Dunn, 2008, p. 252). Importantly, this ability underpins the consistent delivery of non-linear reasoning and non-standard solutions that achieve optimal results for individual clients over time. In sum, prominent figures, including leaders of the competence agenda (i.e., Kaslow et al., 2007), have suggested that those who need to adapt to new contexts, create new knowledge in these contexts, and continually improve their performance and professionalism require more than competence to be the best that they can be; whether that is capability or, on the basis of its' apparent conceptual overlap, adaptive expertise. Indeed, there appear to be notable similarities between the definition of capability and the definition of adaptive expertise; particularly around the adaptation to new situations and generating new learning. However, as trainees also often need to adapt and generate new knowledge, why wouldn't we place an early and explicit emphasis on these constructs if they can help to later break the apparent "thinking ceiling" of competence?

We suppose that some advocates of competence might argue that it is not a matter of competence versus expertise but rather one of timing. In other words, trainees have to begin somewhere and so should acquire a baseline level of competence first and then capability (or adaptive expertise) can develop through learning and development after formal training (e.g., Fletcher \& Maher, 2014). In line with this, Kaslow et al. (2007) have suggested that those who possess higher levels of capability "are likely to be classified as experts" (p. 447); in 
other words, those who have reached the upper echelons of ASP performance. However, if we know the outcomes that represent capability (i.e., adapting to new contexts, creating new knowledge, and progressive performance), then why would we not try to accelerate the skills that underpin them during training rather than wait for their hopeful emergence via lifelong learning after training? Our guess here is that advocates of competence (and competencies) might argue that such a focus would hinder the acquisition of common minimum standards across trainees. However, we are unsure why a trainee would be any more likely to fail to meet minimum standards by being placed in unfamiliar contexts and situations, required to understand and "solve" these novel situations, provided with formative and summative feedback, and encouraged to engage in self-assessment (as per the methods of capability development outlined above by Kaslow et al., 2007). In fact, is this not what most supervisors are doing with their trainees already? Significantly, much work has also defined the skills that underpin capability (or adaptive expertise) and how their development can be accelerated; thus providing a clear and specific guide on what trainee experiences should aim to achieve (Fiore, Hoffman, \& Salas, 2008). In sum, and leading onto the second advantage of being expertise-equipped, literature on expertise provides a stronger empirical base than that on competence for developing adaptable professionals.

\section{Advantage II: A Stronger Empirical Base for Developing Adaptable Practitioners}

Although Epstein and Hundert's (2002) definition of competence details the need for strong thinking skills, the level of explicit study, promotion, and assessment of these skills has been limited in the competence literature, and certainly in competency-based assessments which almost explicitly avoid evaluation of thinking in favour of behavioural observation (cf. Fouad et al., 2009; Goldsmith, 1999). In contrast, the primary goal of work on expertise has been to understand how individuals effectively gather, process, and act upon information. Based on a breadth of literature (e.g., Feltovich, Prietula, \& Ericsson, 2006; Gott, Hall, 
Pokorny, Dibble, \& Glaser, 1992; Hoffman, 1998; Hill, Spiegel, Hoffman, Kivlighan, \& Gelso, 2017; Holyoak, 1991; Kahneman \& Klein, 2009; Nash, Martindale, Collins, \& Martindale, 2012; Norcross \& Karpiak, 2017; Shanteau, 1992; Shanteau \& Weiss, 2014; Tracey et al., 2014), those with higher levels of expertise have consequently been found to possess or employ higher levels of the following than those with lower expertise (NB. features which should inform the learning outcomes of expertise-based training in ASP):

- a declarative knowledge base that is deep, complex, conceptual, integrated (i.e., in “chunks"), and hierarchically organised;

- an ability to develop abstract and functional rather than descriptive representations of a challenge or problem (i.e., understanding why a situation has arisen and how the relevant factors interact, rather than just what the situation is or factors are);

- greater domain / task-specific knowledge and applications (i.e., the further another domain or task is from the practitioner's areas of expertise, the less transfer);

- mental models and routines that gather, manage, and interpret essential information (and cull less relevant details);

- perceptual skills that strategically detect the most relevant patterns in situations where details are usually partial, changing, and knotted; leading to an economy of effort, especially with more familiar tasks;

- a sense of typicality that supports anomaly detection and so the need to adapt;

- $\quad$ selective access to (and retention of) relevant information in long-term memory;

- an ability to form multiple representations and interpretations of a challenge, thus supporting the revision of old strategies and creation of new strategies for problem-solving;

- case-based reasoning, where the current situation or challenge is compared to prior cases of a similar nature; 
- automaticity in decision making / skilled intuition;

- a strong use of reflection (both on- and in-practice), exploration of alternatives in strategy and delivery, and hypotheses-driven experimentation;

- an awareness of personal strengths and limitations, and;

- a motivation for / commitment to deliberate practice and lifelong learning that yields improvements in performance.

In sum, this list of features reflects the product of an explicit, cognitively-oriented agenda that has built detailed knowledge on what is needed to face variety, complexity, and uncertainty in one's field; features which, as we have already stressed, are ubiquitous in ASP. Importantly, these cognitive subskills are also amenable to systematic training (Fadde, 2009); a point that we shall pick up on later. Returning to our main point, however, we struggle to see how an argument can be made that the breadth and depth of knowledge on cognitive skills is greater, let alone equivalent, in the literature on competence which has, as far as we are aware, undertaken little exploration of specifics in cognitive processing and its development; which is surely what would be needed for evidence-informed training (that targets adaptable practitioners) to assume a competence rather than expertise focus?

\section{Advantage III: Adopting a Longer-Term, More Practitioner-Centred (Rather than a Shorter-Term, More System-Centred) Philosophy}

The final advantage of the expertise approach is the focus and nature of development that it can fundamentally support. Specifically, the underpinning philosophy of research on expertise has been to identify subjectively-experienced skills that can help individuals to get better at specific tasks. In contrast, the underpinning philosophy of work on competence including the push for a "culture of competence" (Kaslow et al., 2007) - has been to identify objectively-measurable standards that can help the profession (or our administrators?) to get the collective field better or more accountable (Kaslow et al., 2007). More specifically, and 
reflecting the current approach by ASP training bodies, the goal to train via standardisation is perhaps best illustrated by competency-based frameworks; or those which list the "performance capabilities needed to demonstrate knowledge, skill and ability (competency) acquisition” (Dooley, Lindner, Dooley, \& Alagaraja, 2007, p. 317). On this basis, Fletcher and Maher (2014) have previously asserted:

It is imperative that the profession of sport psychology defines threshold levels of competence for different stages of development. It is important that such a lifelong approach to competence development articulates the competencies and behavioral anchors best suited at various points in the professional career trajectory and that ultimately lead to the development of expert practitioners. (p. 175)

In short, the primary approach in competence-based training has been to define what practice objectively looks like at different stages to help trainees reach similar baseline standards. Of course, this focus is not inherently "wrong”. However, it does reflect a philosophy that has particular consequences for practitioners and, most importantly, our clients.

As an example of these consequences, consider the following suggestion:

Attempting to compare competencies in terms of their importance is an unhelpful distraction from what needs to be done: namely, define each competency, break them down into their essential components [note the contrast with the "chunking" focus of expertise], and define the behavioral anchors that demonstrate the threshold of competent performance at each level of development. By taking this approach, one can see the progress of knowledge, skill, and attitude expected within a competency area (e.g., from basic to advanced record keeping, decision making, etc.) and across difference stages of development (e.g., novice, expert, etc.) [emphasis added]. (Fletcher \& Maher, 2014, p. 178) 
Leaving the worrying (or dangerous?) idea that record keeping is generally as important for a psychologist as decision making, our question is not whether this approach can make trainees better (or comparable), learn more, and understand their strengths and weaknesses; in fact, we already know that it can given prior literature (e.g., Hoffman, 1998; Falender \& Shafranske, 2007) and, presumably, by the continued certification of new practitioners in ASP. For example, competency-based training might be particularly useful for managing trainees who are failing to meet minimum standards (Grus, Falender, Fouad, \& Lavelle, 2016) and as a means for assessors to measure previous and current performance more neatly (Davis \& Hase, 1999; Hutter et al., 2016). Instead, our point is whether this is the best approach for developing trainees with integrated skills who can go on to reach their full potential in complex, unpredictable, and low validity settings. In this regard, it is interesting to note that a number of colleagues in Hutter et al. (2016) felt that defining generalizable behavioral anchors were "hard, or even impossible, to generate" (p. 88), partly because they did not perceive its "feasibility, benefit, or importance" (p. 89). Indeed, working to pre-defined competencies promotes a focus on behaviors, procedural knowledge, and a right or a wrong way to practice (e.g., Belar, 2009; Hutter et al., 2016); a focus which is in direct contrast to the markers of expertise which promote a focus on cognition, declarative knowledge, and an "it depends" approach to assessing the appropriateness of practice. Despite the claims of Fletcher and Maher (2014, p. 173), competency (NB. not competence) models and expertise models are therefore diametrically opposed; or, at the very least, based upon significantly different principles. In fact, Hatano and Inagaki (1986) suggested this over three decades ago:

When the results obtained through performing a [sic] skill have no vital importance or usefulness [e.g., they don't carry a right or wrong way to perform], people tend to produce minor variations in procedural skill and to examine their effects, often 
playfully. That is, they are willing to engage in active experimentation which creates a greater possibility to acquire conceptual [i.e., declarative-rich] knowledge. On the contrary, when a procedural skill is performed primarily to obtain rewards, people are reluctant to take the risk of varying the skill, since they believe that the safest way is to rely on the 'conventional' version. (p. 34)

In short, the point made by Hatano and Inagaki is that our goal structure shapes how we practice and how we develop. So, when individuals are given clear direction on what they should be doing, they run the risk of features that hinder development on a philosophical and epistemological level (Kahneman \& Klein, 2009; Williams, Dunning, \& Kruger, 2013). Namely, trainees can: (a) struggle when tasks vary from the "norm" (which is the norm in applied work!); (b) increase confirmation bias ("I did the right thing as it fits the model"); (c) exaggerate self-assessments; and (d) limit their critical thinking (e.g., "what else could I have done?").

Of further note, working to the knowledge that "the system wants you to have" can lead to issues with the motivation to get better, as suggested by Alexander (2003, p. 12): We have determined that interest, especially individual interest, is tied to students' knowledge and strategic efforts. If the educational experience is too narrowly focused on the acquisition of domain-specific knowledge, without regard to motivational forces, we may be stressing one aspect of expertise to the detriment of others. Thus, schools can do much to nurture emerging competence by allowing students to pursue topics and tasks of interest and by immersing them in meaningful learning experiences that are fertile ground for the growth of enduring interest.

As such, if practitioners are to develop efficiently and reach their full potential, then training needs to develop their fascination with our profession, amongst other key psycho-behavioral 
skills (cf. MacNamara, Button, \& Collins, 2010a, 2010b). For example, Alexander (2003, p.

12) further summarised that:

The journey toward expertise is unceasing. Even those who have attained the knowledge, strategic abilities, and interests indicative of expertise cannot sit idly by as the domain shifts under their feet. We, thus, do a disservice to our learners by conveying the idea that learning some set body of facts or procedures is the educational end.

In contrast to a pursuit of controllable and reliable standards (e.g., Fletcher \& Maher, 2014; Portenga et al., 2016), research on expertise has presented a significantly different view on professional development. More specifically, this work has placed individuals at the heart of the process and prioritised the development of declarative knowledge, thinking processes, and underpinning belief systems (not instead of, but over the procedural knowledge and overt behaviours that have been prioritised by competence literature). For example, recent work on expertise in coaching has described the process of epistemological development (e.g., Grecic \& Collins, 2013, Olsson, Cruickshank, \& Collins, 2017), where emphasis has been placed on helping the practitioner to progress against key outcomes in a more personalised, deep, and flexible way. More specifically, and among other methods, these approaches have placed the discussion, observation, and reflection on actual practice at the centre of the development and assessment process (over written reports, activity logs, or exams) in order to progress the practitioner's ability to practice independently, flexibly, and creatively; as well as learning how to learn for themselves (cf. Phelps, Hase, \& Ellis, 2005). Importantly, such outcomes reflect the markers of expertise presented earlier (see Advantage II: A Stronger Empirical Base for Developing Adaptable Practitioners) and, as such, support a more personalised style of assessment where the practitioner's knowledge and thinking in their particular domain are paramount. Again, we reiterate that the philosophy which has underpinned much literature 
on competence is not wrong; instead, the philosophy that underpins expertise is better suited to the job if we want to develop individuals who are "as good as they can be in the future" rather than those who are "good enough for now". Such focus also aligns with the view that "expertise resides far more in the person ... than in specific methods" (Norcross \& Karpiak, 2017, p. 66), as well as the assumption that "the development of expertise, like all forms of development, is subject to individual differences in psychological and behavioral characteristics" (Hoffman, 1998, p. 83).

\section{Moving Forward with Expertise-Based Training in ASP}

To support an evidence-informed evolution of what the goal of professional training should be in ASP, we hope to have conveyed that there are a number of advantages - in terms of both process and outcome - from targeting and accelerating expertise over competence. More specifically, an expertise focus can: (a) build the potential for our trainees to break the "thinking ceiling" of competence; (b) exploit a stronger empirical base than competence for developing the thinking skills that underpin independent, flexible, and creative practice; and (c) work from a longer-term and more practitioner-centred philosophy than competence. To address our second aim, we now consider how trainees can be equipped with the skills that underpin expertise.

As stated earlier, however, expertise-based training in ASP would certainly not be a new approach; many already target and accelerate expertise in trainees and our literature has started to formalise how this may be best achieved (Martindale \& Collins, 2005, 2007, 2012, 2013). However, as this focus has not yet been systematically required and reinforced by our training systems, or sufficiently studied in the context of ASP, it seems reasonable to suggest that our current understanding and action, as a profession, is both limited and reliant on supervisors and assessors going beyond the current certification orthodoxy (cf. Hutter et al., 2016). As such, we encourage those responsible for practitioner training to heed the key 
principles of developing expertise-based training. Specifically, Fadde (2009) has outlined that: (a) the key cognitive subskills that underpin expertise and expert performance should be revealed through comparison-based study (e.g., expert-novice differences); (b) instructional methods should then be designed that systematically train these skills; and (c) these methods should then be integrated into coherent training programs. Therefore, while expertise is often characterised by tacit knowledge and intuition that has been developed through extensive domain experience, it can be defined and accelerated; where "the general approach is akin to developing 'habits of mind"” (Hutton et al., p. 85). In this respect, Hoffman (1998, p. 94) has previously stated that challenges with developing expertise typically reflect a "training bottleneck" rather than a "knowledge acquisition bottleneck". We now consider some initial ways in which ASP might approach Fadde's principles of expertise-based training.

Reflecting the nature of our arguments up to this point, these recommendations are mainly targeted at how ASP might better facilitate expertise in trainees on a system-level.

\section{Strand One: Identifying the Specific Subskills of Expertise}

To support the first of Fadde's (2009) steps and help training bodies to establish new, cognitive-based standards for certification, cognitive task analysis would appear to provide a particularly useful approach for building on the markers of expertise established by previous research in other domains (see Advantage II) and identifying those specific to different levels of proficiency in ASP (Martindale \& Collins, 2010). More specifically, applied cognitive task analysis (hereafter ACTA: Militello \& Hutton, 1998) is focused on extracting the cognitive demands of a task alongside the skills needed to effectively negotiate it. To do so, it first uses a task diagram interview to generate a broad overview of a task and its most difficult elements; secondly, a knowledge audit is conducted to identify the aspects of expertise (e.g., perceptual cues, cognitive strategies) that are required to perform the task and, in particular, its difficult elements (including why these are felt to be difficult); finally, a 
simulation interview is undertaken to explore the identified cognitive processes in a specific scenario, therefore generating knowledge on how skills are played out in a practical sense and errors that might be typically made. In this manner, ACTA is well suited to dig deeper than a competency-based job task analysis that elicits what practitioners know and do (Portenga, Ayoagi, \& Cohen, 2016; Watson \& Portenga, 2014) and reveal how and why practitioners across different levels of performance and different perspectives (e.g., cognitive-behaviorist, humanist, existentialist) think through core tasks, such as case formulation, support program design, and even specific types of interventions in certain ways (e.g., disputing irrational beliefs in REBT). Indeed, building on work that has started to identify key cognitive strategies in ASP (e.g., "nested thinking”: Collins \& Cruickshank, 2015; Martindale \& Collins, 2012), more recent research has used ACTA to highlight several nuances of intervention delivery (e.g., regarding situation assessment and use of critical cues) which have been previously unexplored in the literature (Vardal \& Martindale, 2017).

\section{Strand Two: Instructional Methods for Developing Expertise}

In terms of methods to systematically train the cognitive subskills of expertise (as per the second step outlined by Fadde, 2009), training bodies in ASP would do well to draw upon the wide body of literature across other domains in psychology on accelerated expertise and the performance of complex tasks (e.g., Gore, Flin, Stanton, \& Wong, 2015; Hoffman et al., 2014). In particular, Ward et al. (2017) have identified six evidence-based principles for accelerating adaptive performance skill. These principles are: flexibility-focused feedback (e.g., provision of feedback which permits learners to quickly reassess or reappraise their interpretation of a situation in flexible ways, including adding to it, subtracting from it, or abandoning for a new conception); concept-case coupling (e.g., combining context and cognition so that the more cases are encountered, and the more varied these cases are, the more likely the concept will be learned flexibly); tough case time compression (e.g., 
presentation of particularly difficult or low frequency scenarios to increase challenging learning opportunities); case-proficiency scaling (e.g., a library of tough cases to be scaled to the trainees proficiency level to permit current skills to be stretched); complexity preservation (e.g., learning with complexity to facilitate adaptation to novel or changing demands rather than over simplified scenarios which train procedures); and active reflection (e.g., to facilitate critical thinking, reflective practice and metacognitive awareness such as estimation, experimentation, extrapolation, and explanation). The application of these training principles are likely to be in the context of tools that training systems encourage trainers, supervisors, or mentors to deploy and the approach is akin to developing the mental models which are required to adapt (Ward et al., 2017). Of course, training bodies should also include these principles within assessment. For example, trainees could be evaluated on their preparation for, performance in, and reflections after a suitably challenging and complex consultation session, either with one of their clients or in a simulation. Importantly, this approach would also allow assessors to better contribute to the trainee's development by offering the chance to provide flexibility-focused feedback and support the active reflection process (cf. Hutter et al., 2016).

In this vein, the training principles of Ward et al. (2017) stress the need for scenarioand problem-based training that provides context-rich challenges to trainees (Fadde, 2009), particularly through consideration of tough or atypical cases. Indeed, central to developing adaptive performance is the chance to practice problems that stretch one's current skills in a variety of "safe-to-fail" environments. In short, practice that primarily exposes and stretches one's thinking process (Ward et al., 2018). Additionally, scenario-based training provides a strong platform for trainees to talk through their thinking, including the options that they have considered and their weighting criteria. The trainee's supervisor, assessor, or peers can then use subsequent conversations to enable their cognitive apprenticeship, where the trainee can 
compare and contrast thinking structures and processes to their colleagues (Collins, Brown \& Holum, 1991; Fadde, 2009). In line with this, Kaslow et al. (2007, p.443) have argued that problem-based learning is important because it provides an opportunity for students to engage in crucial cognitive work:

[Problem-based learning can help students to] reflect on what they do and do not know about the person's problems, develop hypotheses, pursue answers to questions that pique their curiosity and facilitate problem solving, share with their peers what they have learned from their research and data collection, and articulate how they would address the individual's difficulties ... . It offers a valuable methodology for assessing critical thinking, judgment, emotional intelligence, interpersonal interactions, and capacity to think and behave like a professional psychologist. Inherent within problem- and scenario-based learning is, of course, an emphasis on a trainee's judgment and decision making skills. Indeed, all of the markers of expertise listed earlier (see Advantage II) ultimately relate to PJDM and reflect the fact that ASP is largely a series of decisions. Of course, PJDM isn't the only non-technical skill necessary for effective practice. However, reflection on the macro-cognition needed to think effectively in natural settings, such as ASP, stresses that this aspect of practice is anything but the "narrow focus" suggested by some colleagues (Fletcher, 2017, p. 72). Instead, PJDM is central to sense making, planning, problem detection, adaptation, co-ordination, managing attention, identifying leverage points, managing risks and uncertainty, mental simulation and story building, developing mental models, and maintaining common ground (Crandall et al., 2006). Thus, expertise and PJDM are inextricably entwined - as best illustrated in the origins and evolution of the naturalistic decision making literature (e.g., Kahneman \& Klein, 2009).

To illustrate, while competency-based training places more emphasis on observables such as "listens and is empathic with others" and "effectively negotiates conflictual, difficult 
and complex relationships" (Fouad et al., 2009, p. S12), expertise-based training places less emphasis on 'outputs' (i.e., observed behaviours) and more on the "PJDM production line" (i.e., the thinking behind the behaviours). Continuing with the relationship example above, expertise-oriented supervisors and assessors would therefore be much more interested in the trainee's responses to questions such as why did you relate to that individual in that way at this time? What alternatives were available and considered? To relate to the client in another way, what would have to have been different? What cues or information did you pick up in the conversation, and what assessments did you make, to amend your judgments and actions? What are you anticipating for your next interaction? In this way, a focus on PJDM aids the development of declarative over procedural knowledge; or, the type of knowledge that drives the ability to adapt to new contexts, cope with complicated and unfamiliar tasks, generate new knowledge, and continue to raise levels of performance (Anderson, 1982). It also means that competency models can then guide us on what a trainee could learn, know, or do after assessment rather than what they should learn, know, or do (Collins et al., 2014).

\section{Strand Three: Coherent Training Systems}

Of course, and as outlined by Fadde (2009), the impact of an expertise agenda in ASP will only be optimized if the subskills of expertise and supporting methods are systematically promoted. In this respect, we are well aware that achieving this will require a major change in approach from professional bodies who have committed to competency-based training and "paper-heavy", anonymised assessment, perhaps because of similar "evolutions" in parallel professions such as coaching (Collins et al., 2014). For example, expertise-based training would require much more interaction between the trainee and their assessors so that the rationale behind the trainee's practice might be explored in detail. This would logically involve the assessors regularly observing the trainee in actual practice scenarios (McKinley, Fraser, \& Baker, 2001; Nelson, 2007) and working in far closer partnership with supervisors. 
More broadly, responsible bodies would also need to place greater attention on the training of supervisors given the major differences between doing ASP and training ASP. Certainly, supervision is a specialized role and should thus require specialized understanding of how expertise develops (cf. Olsson et al., 2017). At present, however, the process for becoming a supervisor in many systems is somewhat brief, narrow, shallow, and focused on technical aspects. Greater focus on the cognitive skills that enable adaptive expertise would also require changes to the wider ASP training system. For example, if the final phase of supervision is to adopt an expertise focus then higher education will need to do more to help our future practitioners to get up to speed on a cognitive level. Similarly, there is also a need for our professional bodies to reassess the requirements of development after formal qualification to promote the continued progression of one's cognitive skills and limit the scale of stagnation, skill decay, and performance decline (Ward, Suss \& Basevitch, 2009). We might argue that re-accreditation should be more than a mere listing of one's client interactions and CPD experiences, but that's another paper!

\section{Concluding Comments}

In light of the inconsistencies that still surround professional training in ASP, we hope to have conveyed, with both theory and evidence, that an expertise-based agenda can: (a) build the potential of trainees to break the "thinking ceiling" of competence; (b) exploit a stronger empirical base than competence for developing skills that underpin independent, flexible, and creative practice; and (c) enable a longer-term and more practitioner-centred philosophy than competence. We also hope to have conveyed what is needed to start the process of progressing an expertise-based agenda, including a strong reinforcement of the role played by PJDM. On this basis, we hope that this paper might help to support an evidence-informed evolution of our training systems, plus further work on tools, methods, techniques, and experiences that can enhance expertise within and across levels of 
proficiency in ASP (cf. Fiore et al., 2008). Indeed, it is what our profession but, most importantly, our clients deserve.

\section{References}

Alexander, P. A. (2003). The development of expertise: The journey from acclimation to proficiency. Educational Researcher, 32(8), 10-14. doi:

\subsection{2/0013189X032008010}

Anderson, J. R. (1982). Acquisition of cognitive skill. Psychological Review, 89, 369-406.

Association for Applied Sport Psychology (2017). Candidate handbook: CMPC certification program. Retrieved from:

http://www.appliedsportpsych.org/certification/certification-program-candidatehandbook/

Belar, C. D. (2009). Advancing the culture of competence. Training and Education in Professional Psychology, 3, S63-S65. doi: 10.1037/a0017541

British Psychological Society (2018). Qualification in sport and exercise psychology (stage 2): Candidate handbook. Retrieved from: https://www.bps.org.uk/psychologists/society-qualifications/qualification-sport-andexercise-psychology-stage-2

Collins, A., Brown, J. S., \& Holum, A. (1991). Cognitive apprenticeship: Making thinking visible. American Educator, 6(11), 38-46.

Collins, D., Burke, V., Martindale, A., \& Cruickshank, A. (2015). The illusion of competency versus the desirability of expertise: Seeking a common standard for support professions in sport. Sports Medicine, 45, 1-7. doi: 10.1007/s40279-014-0251-1

Collins, L,. \& Collins, D. (2016). The foci of in-action professional judgment and decisionmaking in high-level adventure sports coaching practice, Journal of Adventure Education and Outdoor Learning. doi: 10.1080/14729679.2016.1227717 
Collins, D., \& Cruickshank, A. (2015). Take a walk on the wild side: Exploring, identifying, and developing consultancy expertise with elite performance team leaders. Psychology of Sport \& Exercise, 16, 74-82. doi:10.1016/j.psychsport.2014.08.002

Crandall, B., Klein, G., \& Hoffman, R. R. (2006). Working minds: A practitioner's guide to cognitive task analysis. London: The MIT Press.

Davis, L., \& Hase, S. (1999). Developing capable employees: the work activity briefing. Journal of Workplace Learning, 8, 35-42.

Dooley, K. E., Lindner, J. R., Dooley, L. M., \& Alagaraja, M. (2007). Behaviorally anchored competencies: evaluation tool for training via distance. Human Resource Development International, 7, 315-332.

Ericsson, K. A. (2009). Development of professional expertise: Toward measurement of expert performance and design of optimal learning environments. New York: Cambridge University Press.

Epstein, R. M., \& Hundert, E. M. (2002). Defining and assessing professional competence. JAMA: Journal of the American Medical Association, 287, 226-235. doi:10.1001/jama.287.2.226

Eubank, M. (Ed.). (2016). Professional training in sport and exercise psychology [Special Issue]. Sport \& Exercise Psychology Review, 12(2).

Fadde, P. J. (2009). Expertise-based training: Getting more learners over the bar in less time. Technology, Instruction, Cognition and Learning, 7, 171-197.

Falender, C. A., \& Shafranske, E. P. (2007). Competence in competency-based supervision practice: Construct and application. Professional Psychology: Research and Practice, $38,232-240$.

Fazey, I., Fazey, J. A., \& Fazey, D. M. A. (2005). Learning more effectively from experience. Ecology \& Society, 10(2): 4. 
Feltovich, P. J., Prietula, M. J., \& Ericsson, K. A. (2006) Studies of expertise from psychological perspectives. In K. A. Ericsson, N. Charness, P. J. Feltovitch, \& R. R. Hoffman (Eds.), The Cambridge Handbook of Expertise and Expert Performance (pp. 41-67). New York: Cambridge University Press.

Fiore, S. M., Hoffman, R. R., \& Salas, E. (2008). Learning and performance across disciplines: An epilogue for moving multidisciplinary research toward an interdisciplinary science of expertise. Military Psychology, 20, S155-S170. doi:10.1080/0899560070180493

Fitzpatrick, S. J., Monda, S. J., \& Wooding, C. B. (2016). Great expectations: career planning and training experiences of graduate students in sport and exercise psychology. Journal of Applied Sport Psychology, 28, 14-27. doi:10.1080/10413200.2015.1052891

Fletcher, D. (2017). Supervisor commentary. Sport \& Exercise Psychology Review, 12(2), 72. Fletcher, D., \& Maher, J. (2013). Toward a competency-based understanding of the training and development of applied sport psychologists. Sport, Exercise, and Performance Psychology, 2, 265-280. doi:10.1037/a0031976

Fletcher, D., \& Maher, J. (2014). Professional competence in sport psychology: Clarifying some misunderstandings and making future progress. Journal of Sport Psychology in Action, 5, 170-185. doi:10.1080/21520704.2014.965944

Fouad, N. A., Grus, C. L., Hatcher, R. L., Kaslow, N. J., Hutchings, P. S., Madson, M. B., . . . Crossman, R. E. (2009). Competency benchmarks: A model for understanding and measuring competence in professional psychology across training levels. Training and Education in Professional Psychology, 3, S5-S26.doi:10.1037/a001583Fraser, S., \& Greenhalgh, T. (2001). Coping with complexity: Educating for capability. British Medical Journal, 323, 799-803. 
Gardner A., Hase, S., Gardner, G., Carryer J., \& Dunn, S. V. (2008). From competence to capability: a study of nurse practitioners in clinical practice. Journal of Clinical Nursing, 17, 250-258.

Goldsmith, S. (1999). Beyond competencies in Australian nursing. Australian Electronic Journal of Nursing Education, 5.

Gore, J., Flin, R., Stanton, N., \& Wong, W. (2015). Applications for naturalistic decision making. Journal of Occupational \& Organizational Psychology, 88, 223-230.

Gott, S., Hall, P., Pokorny, A., Dibble, E., \& Glaser, R. (1992). A naturalistic study of transfer: Adaptive expertise in technical domains. In D. Detterman \& R. Sternberg (Eds.), Transfer on trial: Intelligence, cognition, and instruction (pp. 258-288). Norwood, NJ: Ablex.

Grecic, D., \& Collins, D. (2013). The epistemological chain: practical applications in sports. Quest, 65, 151-168. doi:10.1080/00336297.2013.773525

Grus, C. L., Falender, C., Fouad, N. A., \& Lavelle, A. K. (2016). A culture of competence: A survey of implementation of competency-based education and assessment. Training and Education in Professional Psychology, 10, 198-205. doi:10.1037/tep0000126

Hatano, G., \& Inagaki, K. (1986). Two courses of expertise. In H. Stevenson, H. Azuma, \& K. Hakuta (Eds.), Child development and education in Japan (pp. 262-272). New York: W. H. Freeman.

Hill, C. E., Spiegel, S. B., Hoffman, M. A., Kivlighan, D. M., \& Gelso, C. J. Therapist expertise in psychotherapy revisited. The Counseling Psychologist, 45, 7-53. doi: org/10.1177/0011000016641192

Hoffman, R. R. (1998). How can expertise be defined? Implications of research from cognitive psychology. In R. Williams, W. Faulkner, \& J. Fleck (Eds.), Exploring expertise (pp. 81-100). New York: Macmillan. 
Hoffman, R. R., Ward, P., Feltovich, P. J., DiBello, L., Fiore, S. M., \& Andrews, D. H. (2014). Accelerated expertise: Training for high proficiency in a complex world. New York: Psychology Press.

Holyoak, K. J. (1991). Symbolic connectionism: Towards third-generation theories of expertise. In K. A. Ericsson \& J. Smith (Eds.), Toward a general theory of expertise: Prospects and limits (pp. 301-335). New York: Cambridge University Press.

Hutter, R. I., Oldenhof-Veldman, T., Pijpers, J. R., \& Oudejans, R. D. (2017). Professional development in sport psychology: Relating learning experiences to learning outcomes. Journal of Applied Sport Psychology, 29, 1-16. doi:10.1080/10413200.2016.1183152

Hutter, R. I., Pijpers, J. R., \& Oudejans, R. R. D. (2016). Assessing competence in sport psychology: an action research account. Journal of Sport Psychology in Action, 7, 8097.

Kahneman, D., \& Klein, G. (2009). Conditions for intuitive expertise: A failure to disagree. The American Psychologist, 64, 515-526. doi:10.1037/a0016755.

Kaslow, N. J., Rubin, N. J., Bebau, M. J., Leigh, I. W., Lichtenberg, J. W., Nelson, P. D., ... Smith, I. L. (2007). Guiding principles and recommendations for the assessment of competence. Professional Psychology: Research and Practice, 38(5), 441-451. Doi:10.1037/0735-7028.38.5.441Kennedy, E. K., Cameron, R. J., \& Monsen, J. (2009). Effective consultation in educational and child psychology practice: professional training for both competence and capability. School Psychology International, 30, 603-625.

MacNamara, Á., Button, A., \& Collins, D. (2010a). The role of psychological characteristics in facilitating the pathway to elite performance Part 1: Identifying mental skills and behaviors. The Sport Psychologist, 24, 52-73. doi: 10.1123/tsp.24.1.52 
MacNamara, Á., Button, A., \& Collins, D. (2010b). The role of psychological characteristics in facilitating the pathway to elite performance Part 2: Examining environmental and stage-related differences in skills and behaviors. The Sport Psychologist, 24, 74-96. doi: /10.1123/tsp.24.1.74

Martin, E. A., Winter, S., \& Holder, T. (2017). An exploration of trainee practitioners' experiences when using observation. The Sport Psychologist, 31, 160-172. doi:10.1123/tsp.2016-0019

Martindale A., \& Collins, D. (2005). Professional judgment and decision making: The role of intention for impact. The Sport Psychologist, 19, 303-17. doi:10.1123/tsp.19.3.303

Martindale A., \& Collins, D. (2007). Enhancing the evaluation of effectiveness with professional judgment and decision making. The Sport Psychologist, 21, 458-74. doi:10.1123/tsp.21.4.458

Martindale, A., \& Collins, D. (2010). But why does what works work? A response to Fifer, Henschen, Gould, and Ravizza. The Sport Psychologist, 24, 113-116.

Martindale A., \& Collins, D. (2012). A professional judgment and decision making case study: Reflection-in-action research. The Sport Psychologist, 26, 500-518. doi: $10.1123 /$ tsp. 26.4 .500

Martindale A., \& Collins, D. (2013). The development of professional judgment and decision making expertise in applied sport psychology. The Sport Psychologist, 27, 390-398. doi:10.1123/tsp.27.4.390

Militello, L. G., \& Hutton, R. J. B. (1998). Applied cognitive task analysis (ACTA): a practitioner's toolkit for understanding cognitive task demands. Ergonomics, 41, $1618-1641$. 
Nash, C., Martindale, R., Collins, D., \& Martindale, A. (2012). Parameterising expertise in coaching: Past, present and future. Journal of Sports Sciences, 30, 985-994. Doi:10.1080/02640414.2012.682079

Norcross, J. C., \& Karpiak, C. P. (2017). Our best selves: Defining and actualizing expertise in psychotherapy. The Counseling Psychologist, 45, 66-75. doi: org/10.1177/0011000016655603

Olsson, C., Cruickshank, A., \& Collins, D. (2017). Making mentoring work: The need for rewiring epistemology. Quest, 69(1), 50-64. doi: 10.1080/00336297.2016.1152194

Poczwardowski, A. (2017). Deconstructing sport and performance psychology consultant: Expert, person, performer, and self-regulator. International Journal of Sport and Exercise Psychology. Advance online publication. doi:10.1080/1612197X.2017.1390484

Portenga, S. T., Ayoagi, M. W., \& Cohen, A. B. (2016). Helping to build a profession: a working definition of sport and performance psychology. Journal of Sport Psychology in Action, 8, 47-59. doi:10.1080/21520704.2016.1227413

Phelps, R., Hase, S., \& Ellis, A. (2005). Competency, capability, complexity and computers: Exploring a new model for conceptualising end-user computer education. British Journal of Educational Technology, 36, 67-85.

Psychology Board of Australia (2018). Guidelines on area of practice endorsements. Retrieved from: http://www.psychologyboard.gov.au/

Shanteau, J. (1992). Competence in experts: The role of task characteristics. Organizational Behavior and Human Decision Processes, 53, 252-266. doi:10.1016/07495978(92)90064-E

Shanteau, J., \& Weiss, D. J. (2014). Individual expertise versus domain expertise. American Psychologist, 69, 711-712. doi:10.1037/a0037874 
Stephenson, J., \& Yorke, M. (1998). Capability and quality in higher education. Kogan Page: London

Tozer, M., Fazey, I., \& Fazey, J. (2007). Recognising and developing adaptive expertise within outdoor and expedition leaders. Journal of Adventure Education and Outdoor Learning, 7, 55-75. doi:10.1080/14729670701349780

Tracey, T. J. G., Wampold, B. E., Lichtenberg, J. W., \& Goodyear, R. K. (2014). Expertise in psychotherapy: An elusive goal? American Psychologist, 69, 218-229. doi:10.1037/a0035099

Vardal, O. \& Martindale, A. (2017). Investigating the cognitive demands on experts' decision making in applied sport psychology. The British Psychological Society Division of Sport \& Exercise Psychology Conference 11-12 Dec; Glasgow, UK.

Ward, P., Gore, J., Hutton, R., Conway, G. E., \& Hoffman, R. R. (2017). Adaptive skills as the conditio sine qua non of expertise. Journal of Applied Research in Memory and Cognition. doi: 10.1016/j.jarmac.2018.01.009

Ward, P., Suss, J., \& Basevitch, I. (2009). Expertise and expert performance-based training (ExPerT) in complex domains. Technology, Instruction, Cognition and Learning, 7, 121-145.

Watson, J.C., \& Portenga, S. T. (2014). An overview of the issues affecting the future of certification in sport psychology. Athletic Insight, 6, 261-276.

Williams, E. F., Dunning, D., \& Kruger, J. (2013). The hobgoblin of consistency: algorithmic judgment strategies underlie inflated self-assessments of performance. Journal of Personality and Social Psychology, 104, 976-994. 